\author{
A Hanseníase e a sua Quimioterapia \\ Boechat, N.; Pinheiro, L. C. S. \\ Rev. Virtual Quim., 2012, 4 (3), 247-256. Data de publicação na Web: 18 de junho de 2012 \\ http://www.uff.br/rvq
}

\title{
Leprosy and its Chemotherapy
}

\begin{abstract}
Leprosy is a neglected tropical disease infectious, present in 141 countries and territories around the world. In 2010 were diagnosed around 245 thousand new cases, leaving Brazil as the 2 nd largest number of cases worldwide. The first treatment of leprosy began in the $40 \mathrm{~s}$ with the development of dapsone, rifampicin and clofazimine. They were used as monotherapy presenting side effects and resistance to $M$. leprae. To overcome this problem the World Health Organization (WHO) introduced MultiDrug Therapy (MDT), which has shown to be quite effective, however the goal of leprosy elimination was still not achieved. Thus, there is the emerging need to search for new drugs that could be selective, effective and less toxic. This review presents historical aspects and relevance of this disease as well as recent advances from research on synthetic compounds and the current chemotherapy.
\end{abstract}

Keywords: Leprosy; chemotherapy; neglected diseases.

\section{Resumo}

A hanseníase é uma doença infecciosa tropical negligenciada, presente em 141 países e territórios ao redor do globo. Em 2010 foram diagnosticados cerca de 245 mil novos casos no mundo. O Brasil foi o segundo país com o maior número de casos. O primeiro tratamento da hanseníase começou nos anos $40 \mathrm{com}$ o desenvolvimento da dapsona, rifampicina e clofazimina. Estas drogas foram usadas em monoterapia apresentando efeitos colaterais e resistência ao $M$. leprae. Para superar este problema, a Organização Mundial de Saúde (OMS) introduziu a poliquimioterapia (PQT), que tem se mostrado bastante eficaz, embora a meta de eliminação da hanseníase não tenha sido atingida. Desta forma, existe a necessidade urgente de se pesquisar novos fármacos que sejam seletivos, mais eficazes e menos tóxicos. Esta revisão aborda os aspectos históricos e a relevância desta doença, assim como os avanços recentes da pesquisa sobre compostos sintéticos e a quimioterapia atual.

Palavras-chave: Hanseníase; quimioterapia; doenças negligenciadas.

* Fundação Oswaldo Cruz, Instituto de Tecnologia em Fármacos, Departamento de Síntese Orgânica, Manguinhos, 21041-250, Rio de Janeiro, RJ, Brasil.

Mboechat@far.fiocruz.br

DOI: $\underline{10.5935 / 1984-6835.20120020}$

Rev. Virtual Quim. |Vol 4| |No. 3| |247-256| 


\title{
A Hanseníase e a sua Quimioterapia
}

\author{
Núbia Boechat*, Luiz C. S. Pinheiro \\ Fundação Oswaldo Cruz, Instituto de Tecnologia em Fármacos, Departamento de Síntese Orgânica, \\ Manguinhos, 21041-250, Rio de Janeiro, RJ, Brasil. \\ * boechat@far.fiocruz.br
}

Recebido em 2 de fevereiro de 2012. Aceito para publicação em 7 de junho de 2012

1. Introdução

2. Agente etiológico

3. Histórico da hanseníase

4. Classificação

4.1. Formas clínicas da hanseníase

4.2. Reações Hansênicas

\section{Quimioterapia}

5.1. Poliquimioterápicos e Resistência aos Medicamentos

\section{Novos candidatos e novos alvos na terapia da hanseníase \\ 7. Conclusões}

\section{Introdução}

A doença de Hansen, ou hanseníase, foi identificada em 1874, pelo médico norueguês Gerhard Armauer Hansen. ${ }^{1}$ É uma doença infectocontagiosa com evolução lenta e de baixo poder patogênico, causada pelo bacilo Mycobacterium leprae (M. leprae). O diagnóstico da doença pode ser realizado por baciloscopia, biópsia do nervo e através da reação de Mitsuda, entre outras formas de exames. Indivíduos infectados apresentam sinais e sintomas dermatoneurológicos característicos, que acometem células cutâneas e nervosas periféricas, gerando principalmente lesões cutâneas com diminuição de sensibilidade térmica, dolorosa e tátil, podendo provocar incapacidades físicas, muitas vezes com deformidades, sem falar do estigma e preconceito contra os portadores da doença. $^{2}$
A Organização Mundial de Saúde (OMS) publicou, em 2010, um relatório de 17 doenças tropicais negligenciadas, entre as quais se encontra a hanseníase. ${ }^{3}$ Esses dados mostram que existe um declínio na transmissão da doença desde 2002, quando houve um pico de mais de 620 mil casos registrados. Entretanto, a hanseníase ainda está presente em 141 países. Em 2010, foram diagnosticados cerca de 245 mil novos casos, com prevalência de 212 mil casos; sendo considerado como um problema de saúde pública. ${ }^{4}$ A Índia é o país com maior incidência, cerca de 134 mil, seguido do Brasil com 38 mil novos casos diagnosticados a cada ano, sendo $8 \%$ deles em menores de 15 anos, chegando a uma média de 46 casos por $100 \mathrm{mil}$ habitantes nas regiões Norte e Centro-Oeste. ${ }^{5,6}$ 


\section{Agente etiológico}

A M. leprae, também chamada de Bacilo de Hansen, pertence ao gênero Mycobacterium, família Mycobacteriaceae, e tem crescimento lento. Após a entrada no organismo, localiza-se principalmente na pele e na célula de Schwann. Reproduz-se por fissão binária e é encontrado nos tecidos humanos como bastonetes retos ou ligeiramente encurvados. É um parasita intracelular obrigatório, predominante em macrófagos, aerófilos, Gram-positivo e álcool-ácido resistente, quando corado pelo método de ZiehlNeelsen. Pode manter-se viável por até 10 dias, sob temperatura de $4^{\circ} \mathrm{C}$, fora do organismo humano, em fragmentos de biópsia ou suspensão. Nas secreções nasais, o bacilo pode sobreviver por até sete dias à temperatura de $21^{\circ} \mathrm{C}$. A localização das lesões hansênicas no corpo dos portadores sugere que o bacilo tem preferência por temperaturas menores que $37^{\circ} \mathrm{C}$. Induz necrose caseosa nas células de Schwann, sendo esta a principal causa das deformidades que caracterizam a doença. ${ }^{7}$

\section{Histórico da hanseníase}

Amplamente conhecida pela designação de lepra, a hanseníase tem o seu histórico bem detalhado no Manual de Leprologia ${ }^{8}$, do Ministério da Saúde (MS), de 1960 e, mais recentemente, por Letícia M. Eidt ${ }^{9}$. Acredita-se que a hanseníase tenha sua origem na Ásia ou África. Relatos datando do segundo século antes de Cristo descrevem evidências da doença na Índia, China, Japão e Egito. ${ }^{8,9}$

$\mathrm{Na}$ antiga literatura chinesa e indiana há várias referências sobre enfermidades com sintomas semelhantes aos da hanseníase. Encontram-se descrições de uma doença que provocava a perda de sensibilidade e $o$ aparecimento de manchas vermelhas, que inchavam e depois se ulceravam, ocorrendo em seguida queda de sobrancelhas, rouquidão, cegueira, deformidade nos lábios, mutilação de nariz e diminuição da mobilidade das articulações. Conhecida e descrita também por outros povos - como os hebreus, os egípcios e os assírios - a então denominada lepra, provavelmente foi relacionada a outras doenças de pele, devido a erros durante a tradução dos manuscritos. ${ }^{8,9}$

Por volta de 150 D.C. esta doença era bem conhecida na Grécia e foi lentamente disseminandose pela Europa, possivelmente introduzida por soldados das tropas de Alexandre, o Grande, contaminados pela moléstia, quando retornaram da Índia. ${ }^{8,9}$

Nas Américas a hanseníase provavelmente chegou com os colonizadores franceses, espanhóis e portugueses, tendo o tráfico de escravos como o maior fator de expansão. Entretanto, os imigrantes chineses também contribuíram com a introdução da doença no extremo norte das Américas. ${ }^{8,9}$

No século XVII, foram notificados os primeiros casos da existência da doença de Hansen no Brasil, principalmente nos estados do Rio de Janeiro, Bahia e Pará, chegando posteriormente ao interior. O primeiro asilo para doentes de lepra foi fundado em 1714, no Recife, sem apoio da Coroa Portuguesa, e deu origem ao Hospital de Lázaros, em 1789. No Brasil, àquela época, a assistência aos doentes era feita por instituições de caridade e, assim o governo não tomava conhecimento do progresso da endemia, pois o asilamento era a única medida prática para conter o avanço da doença. ${ }^{8,9}$

O Ministério da Saúde (MS) criou, em 2004, o Programa Nacional de Eliminação da Hanseníase (PNEH) estabelecendo e redirecionando a política de eliminação da doença. As metas do PNEH estabeleciam que: 1) Até dezembro de 2005 as taxas de conclusão do tratamento e de cura deveriam ser superiores a $90 \%$ em todos os estados do país. 2) Para dezembro de 2008, a prevalência e detecção deveriam alcançar a redução de menos de um caso por cada 10 mil habitantes, em pelo menos $50 \%$ dos 2.017 municípios endêmicos, até dezembro de 2005. 3) Já para 2010, a meta de prevalência de menos de um caso por cada 10 mil habitantes deveria ter sido alcançada em todos os municípios do país. ${ }^{10}$ Segundo o MS, em 2010, o coeficiente de detecção geral foi de 1,82 por 10 mil habitantes, correspondendo a 34.894 casos novos da doença no país. Entre 2010 e 2011, o coeficiente de deteç̧ão de casos novos caiu $15 \%$. Os dados preliminares mostraram que, em 2011, houve um coeficiente de 1,58 casos novos por $10 \mathrm{mil}$ habitantes. ${ }^{6}$

\section{Classificação}

A classificação de Madri, adotada pelo MS, diferencia os pacientes acometidos pela hanseníase e indica um tratamento diferenciado para os 2 tipos: 1) paucibacilares (PB) - casos com até cinco lesões de pele e/ou apenas um tronco nervoso comprometido e 2) multibacilares (MB) - casos com mais de cinco 
lesões de pele e/ou mais de um tronco nervoso acometido e com baciloscopia positiva. ${ }^{2,11}$

Indivíduos doentes que apresentam a forma MB são o maior meio de transmissão, pois eliminam o bacilo, através das vias aéreas superiores, durante contatos frequentes. Devido à baixa carga bacilar, as pessoas acometidas pela forma PB não são consideradas importantes fontes de infecção. A hanseníase não é de transmissão hereditária, congênita ou sexualmente transmissível. Ambientes fechados, com pouca luz solar, ausente de ventilação e o contato direto e prolongado com portadores do M. Leprae, sem tratamento, aumentam as chances de infecção. Questiona-se a possibilidade da hanseníase ser transmitida também pelo solo e pelos animais. ${ }^{11,12}$

De acordo com os aspectos bacteriológicos, imunológicos e histológicos a hanseníase apresenta quatro formas clínicas: indeterminada (HI), tuberculoide $(\mathrm{HT})$, virchoviana (HV) e dimorfa (HD). ${ }^{2,11,13}$

\subsection{Formas clínicas da hanseníase}

\section{Hanseníase Indeterminada (HI).}

Considerada a primeira manifestação clínica da hanseníase e não contagiante, em poucos meses ou até anos, ela pode evoluir para a cura espontânea ou para outra forma clínica. Tem como característica máculas hipocrômicas ou áreas circulares de pele aparentemente normal, com distúrbios de sensibilidade, não havendo comprometimento de troncos nervosos, não tendo, assim, ocorrência de incapacidades e deformidades. ${ }^{2,11,14}$

Hanseníase tuberculoide (HT).

Na hanseníase tuberculoide, o grau de resistência ao bacilo é grande e parte dos casos evoluem para cura espontânea. Essa forma caracteriza-se por máculas ou placas em pequeno número, forma e tamanhos variados, bem delimitados e de tom castanho, podendo ser cheias ou apresentando uma borda mais ou menos elevada e o centro plano e hipocrômico, com distúrbios acentuados de sensibilidade nas lesões e observando-se acometimento de troncos nervosos superficiais ou profundos bem como os comprometimentos neurológicos que são específicos para essa forma clínica. A baciloscopia é negativa e a histopatologia revela granulomas tuberculoides que, às vezes, tocam a epiderme, destroem filetes nervosos e os bacilos não são visíveis, a não ser em cortes seriados. A reação de Mitsuda é sempre positiva forte. Os casos tuberculoides são considerados como paucibacilares para tratamento, assim como a hanseníase indeterminada. ${ }^{2,11,14}$

Hanseníase virchoviana (HV).

A hanseníase virchoviana apresenta baciloscopia fortemente positiva, é um foco infeccioso ou reservatório da doença e contribui para a sua multiplicação e disseminação. A HV é uma forma multibacilar, manifestando-se naqueles indivíduos que apresentam imunidade celular deprimida para o M. leprae. A HV caracteriza-se pela infiltração progressiva e difusa da pele, mucosas das vias aéreas superiores, face, caracterizando a face leonina, podendo afetar, ainda, outros órgãos. Os membros também são atingidos onde há comprometimento das superfícies extensoras, articulações, dorso das mãos e extremidades. Com a evolução da doença, múltiplos troncos nervosos são comprometidos levando à perda da função, atrofia muscular, paralisias, deformidades e contraturas. Na forma virchoviana avançada o trato respiratório superior está envolvido, ocasionando perfuração septal e deformidade nasal. ${ }^{2,11,14}$

Hanseníase dimorfa (HD) ou Borderline.

Caracterizada por sua instabilidade imunológica, ela apresenta aspectos de HV e HT, o que faz com que haja grande variação em suas manifestações clínicas tais como numerosas lesões na pele e nervos, com comprometimento sistêmico. A infiltração assimétrica da face, dos pavilhões auriculares e a presença de lesões no pescoço e nuca são elementos sugestivos desta forma clínica. As lesões neurais são precoces, assimétricas e, com frequência, levam a incapacidade física e deformidades. ${ }^{2,11,14}$

\subsection{Reações Hansênicas}

Os estados reacionais ou reações hansênicas são alterações do sistema imunológico, que se exteriorizam como manifestações inflamatórias agudas e subagudas, que podem ocorrer mais frequentemente nos casos MB. Elas podem ocorrer antes, durante ou depois do tratamento com poliquimioterapia (PQT).

São denominadas como reações tipo 1 as que ocorrem em pacientes com predomínio da preservação da imunidade celular específica contra o M. leprae. A reação tipo 2, ou Eritema Nodoso Hansênico (ENH), ocorre em pacientes com imunidade celular pouco preservada ou ausente, sem tratamento específico e eficaz para todos os casos. A piora das lesões neurológicas ocorre durante esses 
episódios e, consequentemente, há aumento das incapacidades podendo acometer vários órgãos. ${ }^{15}$

\section{Quimioterapia}

O primeiro avanço no tratamento da hanseníase ocorreu na década de 40 , com o desenvolvimento da dapsona, o único fármaco até então conhecido, que deteve a doença. A dapsona é um antibacteriano que age através da competição com o ácido paraaminobenzóico (PABA), diminuindo ou bloqueando a síntese do ácido fólico. Entre os vários efeitos colaterais atribuídos a ela destacam-se os problemas digestivos, anemia hemolítica, metemoglobinemia, hepatites, neuropatia motora periférica, fotodermatite e cefaleia. ${ }^{16,17}$

Devido à limitação da monoterapia da dapsona, medicamentos relacionados com atividade antituberculose foram empregados para o tratamento da hanseníase. ${ }^{18,19} \mathrm{Na}$ década de 60 , o antibiótico rifampicina foi utilizado pela primeira vez no combate à $M$. Leprae. Ele age inibindo a síntese proteica bacteriana por combinar-se com a RNA polimerase. ${ }^{20}$ Os efeitos colaterais mais graves causados por este fármaco acontecem quando utilizados de maneira intermitente. São eles: a síndrome pseudogripal, insuficiência respiratória, insuficiência renal, e anemia hemolítica, entre outros. ${ }^{21}$

A clofazimina, que é um antibacteriano, foi inicialmente utilizada em monoterapia e atualmente faz parte do tratamento PQT, existindo poucos relatos de casos de resistência. $O$ seu mecanismo de ação é ignorado. O principal efeito colateral desse fármaco é o ressecamento da pele, podendo evoluir para ictiose, notando-se pigmentação avermelhada da pele além de efeitos adversos gastrointestinais. ${ }^{21,22}$

Etionamida e protionamida são antibacterianos intercambiáveis e semelhantes em suas atividades e toxicidades frente ao bacilo de Hansen. ${ }^{23}$ Nos últimos anos, aumentou o interesse pelo uso da etionamida em regimes PQT. ${ }^{24}$ Quando utilizada diariamente em combinação com a rifampicina, os efeitos hepatotóxicos desse fármaco são potencializados. A etionamida pode ser administrada em pacientes que desenvolvem a pigmentação avermelhada da pele por intolerância à clofazimina. ${ }^{24,25}$

A talidomida embora apresente muitos efeitos adversos, principalmente teratogenicidade ou morte do feto, tornou-se uma grande opção terapêutica para diversas doenças, tais como lúpus eritematoso, doença de Behçet, dermatite atópica, com grande destaque para o quadro clínico de ENH. A talidomida nunca deve ser usada por mulheres que estão grávidas ou que possam engravidar enquanto estiverem em tratamento. ${ }^{15,26} \mathrm{O}$ seu mecanismo de ação varia dependendo da afecção clínica e ainda permanece parcialmente indefinido. Esse fármaco é usado no tratamento do ENH devido à sua atividade anti-inflamatória, principalmente pela inibição da produção de TNF-alfa (Fator de necrose tumoralalfa). ${ }^{27}$

Prednisona é empregada no tratamento de reações hansênicas do tipo 1 e as reações hansênicas tipo 2, ou Eritema Nodoso Hansênico (ENH). ${ }^{15}$

Outros fármacos antibacterianos foram testados para o tratamento da hanseníase com o intuito de diminuir o tempo do tratamento específico. As fluorquinolonas interferem na replicação do DNA bacteriano pela inibição da subunidade $A$ da enzima DNA girase. Embora exista um grande número de fluorquinolonas, apenas as pefloxacina, sparfloxacina e, principalmente a ofloxacina, são descritas como ativas contra o $M$. Leprae. Os efeitos colaterais incluem náusea, diarreia e complicações gastrointestinais. ${ }^{21,23,28}$

Entre as tetraciclinas, a minociclina é o único fármaco da classe que apresenta significante atividade bactericida contra o $M$. Leprae, devido à sua lipofilicidade que permite a penetração na membrana celular. Ela atua inibindo a síntese proteica por uma ligação reversível à subunidade ribossomal $30 S^{23,28}$

A claritromicina é o único antibiótico do grupo dos macrólidos que mostrou ser ativo, por inibir a síntese proteica bacteriana ligando a subunidade ribossomal 50 . $^{23}$

Outros fármacos apresentam atividade conhecida contra o bacilo de Hansen, entre eles o ácido fusídico, pentoxifilina, amoxilina mais ácido clavulânico, brodimoprima e tioacetazona. ${ }^{23}$

\subsection{Poliquimioterápicos e Resistência aos Medicamentos}

Ao contrário da monoterapia que é prolongada e sem perspectivas de término o tratamento através da PQT tem prazo determinado o que aumenta a adesão, diminui os efeitos colaterais e previne a resistência ${ }^{6,21,34}$

Já foi identificada, em muitos países, a resistência inicial e secundária do $M$. leprae à dapsona, através da contaminação de indivíduos com bacilos já 
resistentes. ${ }^{16,29}$ Também foi demonstrada, tratamento da hanseníase ${ }^{32}$. O esquema PQT foi experimentalmente, a resistência secundária à então proposto pela OMS, em 1981, para evitar a rifampicina e ofloxacina, nas décadas de 60 e 90, seleção de cepas resistentes. Foram recomendadas as respectivamente. ${ }^{30,31}$

combinações de três fármacos, conhecida como

Tal fato serviu de alerta para o perigo da perda de um dos medicamentos mais importantes no PQT/OMS, que consiste no uso de dapsona, rifampicina e clofazimina. ${ }^{16}$<smiles>Nc1ccc(S(=O)(=O)c2ccc(N)cc2)cc1</smiles><smiles>CC(=O)CCCCn1c(=O)c2c(ncn2C)n(C)c1=O</smiles>

pentoxifilina

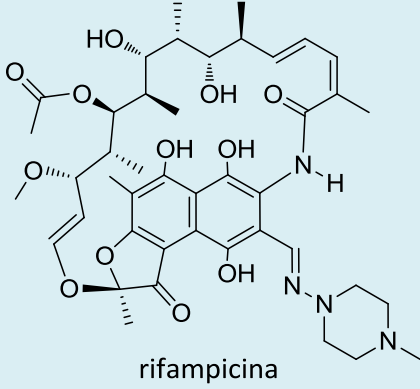

rifampicina<smiles>CCN=c1cc2n(-c3ccc(Cl)cc3)c3ccccc3nc-2cc1Nc1ccc(Cl)cc1</smiles><smiles>CCc1cc(C(N)=S)ccn1</smiles>

etionamida<smiles>CCCc1cc(C(N)=S)ccn1</smiles>

protionamida<smiles>CC1COc2c(N3CCN(C)CC3)c(F)cc3c(=O)c(C(=O)O)cn1c23</smiles>

ofloxacina<smiles>O=C1CC[C@H](N2C(=O)c3ccccc3C2=O)C(=O)N1</smiles>

talidomida<smiles>C[C@]12C=CC(=O)C=C1CC[C@H]1[C@@H]3[C@@H](O)C[C@](C)(C(=O)CO)[C@@H]3CC[C@@H]12</smiles>

prednisona<smiles>NNC(=O)c1ccncc1</smiles>

isoniazida<smiles>CCn1cc(C(=O)O)c(=O)c2cc(F)c(N3CCN(C)CC3)cc21</smiles>

pefloxacina<smiles>C[C@H]1CN(c2c(F)c(N)c3c(=O)c(C(=O)O)cn(C4CC4)c3c2F)C[C@@H](C)N1</smiles>

sparfloxacina<smiles>CN(C)c1ccc(O)c2c1C[C@H]1C[C@H]3C(N(C)C)C(O)=C(C(N)=O)C(=O)[C@@]3(O)C(O)=C1C2=O</smiles>

minociclina

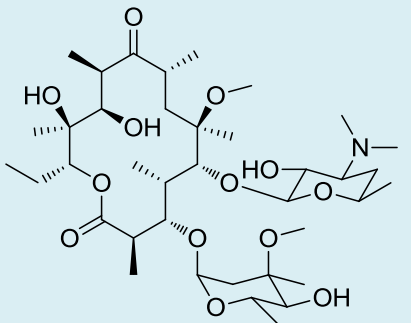

claritromicina

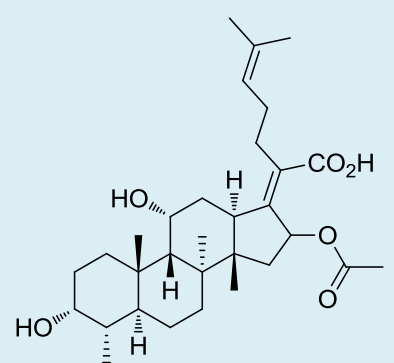

ácido fusídico<smiles>CC1(C)SC(NC(=O)[C@@H](N)c2ccc(O)cc2)C(=O)C1C(=O)O</smiles><smiles>COc1cc(Cc2cnc(N)nc2N)cc(OC)c1Br</smiles>

brodimoprima

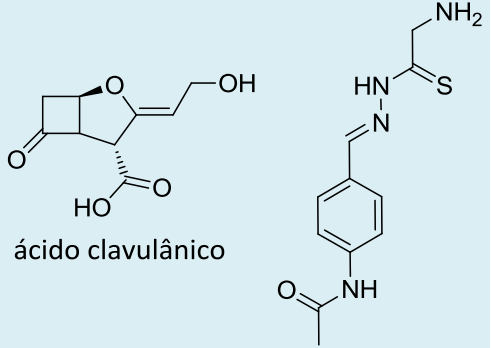

tioacetazona

Figura 1. Fármacos utilizados no tratamento da hanseníase

Os pacientes classificados como PB recebem a combinação de rifampicina e dapsona, conhecida como poliquimioterapia paucibacilar (PQT-PB). Enquanto os pacientes classificados como $\mathrm{MB}$ recebem a combinação tríplice de rifampicina, dapsona e clofazimina, conhecida como poliquimioterapia multibacilar (PQT-MB). , $^{63,34}$
A partir de 1997, a OMS adotou o esquema alternativo ROM, (rifampicina, ofloxacina e minociclina), recomendado para casos paucibacilares com lesão única, sem envolvimento de troncos nervosos. $^{34-36}$

Estudos mostram que a associação dos fármacos claritromicina, minociclina e ofloxacina, ou a combinação com rifampicina/dapsona, podem ser Rev. Virtual Quim. |Vol 4| | No. 3| |247-256| 
utilizados no tratamento das infecções rifampicinaresistentes. ${ }^{19,37,38}$

Para identificar e tratar os casos existentes de resistência ou prevenir o aparecimento e transmissão de bacilos resistentes é necessário estabelecer métodos rápidos para detecção de resistência aos fármacos. No entanto, $M$. leprae não foi cultivada em meios artificiais e, portanto, para identificar padrões de susceptibilidade de fármacos, as bactérias devem ser testadas usando Ensaio de Shepard's, que é um método in vivo, requer um número relativamente grande de bactérias e pelo menos 6 meses. ${ }^{31}$

Outro esquema PQT que não causou efeitos colaterais sérios é conhecido como isoprodian (isoniazida + protionamida + dapsona) associado à rifampicina. $^{24}$

Pacientes que já tenham concluído o tratamento PQT com êxito devem ser acompanhados para diagnostico de possíveis intercorrências. São denominados casos de recidivas os pacientes que pósalta venham eventualmente desenvolver novos sintomas da doença, geralmente causados por tratamento inadequado ou incorreto. ${ }^{34}$

\section{Novos candidatos e novos alvos na terapia da hanseníase}

A epiroprima, um novo inibidor da di-hidrofolato redutase, isoladamente ou em combinação com dapsona e brodimoprima, apresenta atividade contra o $M$. leprae, sugerindo que esse composto poderá ser um candidato à PQT da hanseníase. A atividade bactericida em concentração inibitória mínima da epiroprima contra o $M$. leprae foi de $10 \mu \mathrm{g} / \mathrm{mL}$. Quando combinada com a dapsona, a epiroprima exibiu um sinergismo forte; por outro lado, em combinação com a brodimoprima forneceu apenas efeitos aditivos. $^{39,40}$

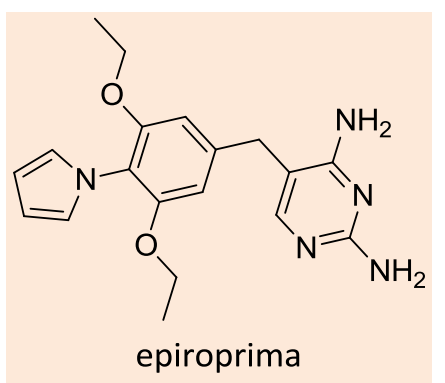

Figura 2. Estrutura química da epiroprima
Haruaki e colaboradores descreveram a atividade in vitro e in vivo anti-M. leprae de novos derivados benzoxazinorifamicina (KRM-1648), em combinação com clofazimina e/ou dapsona. Uma dose combinada de KRM-1648, clofazimina e dapsona apresentaram eficácia mais elevada, reduzindo os valores de índice de crescimento do bacilo. Os testes in vivo mostraram atividade de KRM-1648 superior à rifampicina quando administradas na mesma dosagem. ${ }^{41,42}$

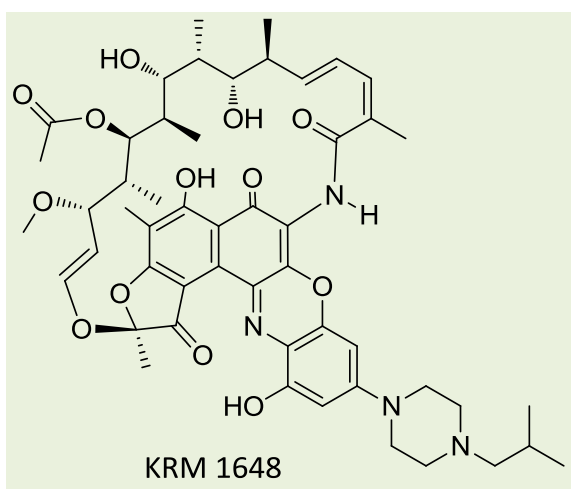

Figura 3. Estrutura química do composto KRM 1648

Enzimas ligases (MurC, MurD, MurE, e MurF) envolvidas na biossíntese da parede celular bacteriana são os alvos mais conhecidos e validados para a terapia antibacteriana. Uma série de derivados sulfonamidas di-hidrogenofosfato (PMDP) já desenvolvidas como inibidoras potenciais para ligases M. leprae Mur foram avaliadas utilizando estudos teóricos. Os resultados sugerem o derivado PMDP EW11 como o melhor inibidor para MurC-Murf ligases. $^{43}$

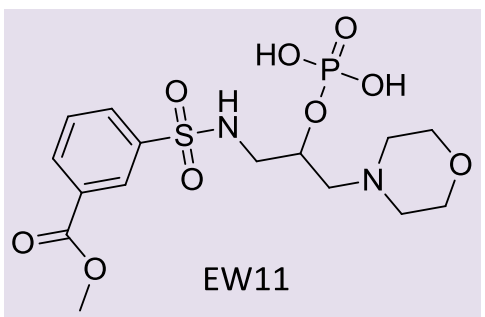

Figura 4. Estrutura química do composto EW 11

A enzima CYP164A1 da família P450 é a única encontrada em $M$. leprae e por isso pode ser um potencial alvo para novos fármacos. Brady e colaboradores descreveram estudos de docking com a enzima CYP164A2, homologa da CYP164A1, em que o derivado econazol foi um inibidor eficaz, podendo assim servir com um protótipo para outros azóis no tratamento da hanseníase. ${ }^{44}$ 
Estudos in vivo com a diarilquinolina R207910 demonstraram que este composto apresenta atividade bactericida promissora frente ao $M$. leprae. ${ }^{45,46}$

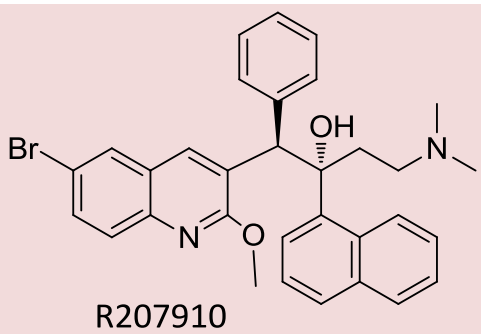

Figura 5. Estrutura química do composto R207910

Os derivados dialquilditiocarbamatos apresentaram atividade antibacteriana frente ao $M$. leprae, in vivo. Comparados com a dapsona, em dose de $30 \mathrm{mg} / \mathrm{kg}$, estes derivados apresentaram inibição significantemente maior. ${ }^{47,48}$
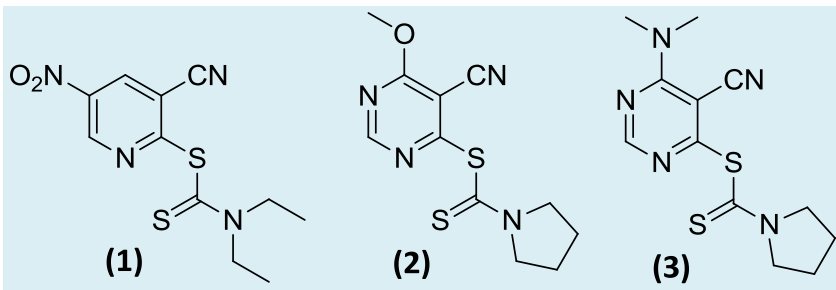

Figura 6. Estrutura química dos derivados dialquilditiocarbamatos (1-3)

Barbosa-Filho e colaboradores revisaram as substâncias de origem natural com atividade anti- $M$. leprae. Os autores destacaram a importância dos já conhecidos bioprodutos, rifampicina, claritromicina e ácido fusídico, bem como de outros 17 fitoquímicos das classes dos lipídios (5), triterpenos (4), macrolidos (2), alcaloides (1), benzenoides (1), flavonoides (1), matansinoides (1), proteides (1) e compostos contendo enxofre (1). ${ }^{49}$

Não há vacina para M. leprae, porém a BCG (bacilo de Calmette-Guérin), utilizada contra a tuberculose, também oferece alguma proteção contra o $\mathrm{M}$. leprae. No Brasil, recomenda-se a administração de BCG em indivíduos que estão em contatos domiciliares com pacientes de hanseníase, independente da idade, exceto para os HIV positivos. Estudos de caso-controle mostraram eficácia e efetividade variáveis da vacina BCG na hanseníase; entretanto, não é recomendado somente o uso da BCG para a prevenção. Ensaios clínicos com adição do bacilo de Hansen morto à vacina BCG para aumentar a resposta imunológica não demonstraram eficácia. ${ }^{21,50}$

\section{Conclusões}

A erradicação da doença de Hansen como problema de saúde pública exige das autoridades um plano de aceleração, de vigilância e de intensificação das ações de eliminação, como diagnóstico precoce e tratamento com a PQT.

Embora os medicamentos utilizados sejam antigos e com graves efeitos colaterais, favorecendo o abandono do tratamento, a formação de cepas resistentes e, por consequência, o crescimento de epidemias, a PQT tem mostrado ser bastante eficaz, com raras recidivas. Mesmo assim, a meta de menos de um paciente para cada $10 \mathrm{mil}$ habitantes não foi atingida. Apesar do declínio dos casos no decorrer dos anos, ainda milhares de pessoas infectadas pelo $M$. leprae são acometidas por essa doença que, se não tratada, pode causar danos progressivos à pele e aos nervos, além da atrofia muscular e da incapacidade permanente. Mesmo assim, o Brasil ocupa o 20 lugar no ranking dos países com altos índices de casos desta doença, que é negligenciada pelas grandes indústrias farmacêuticas, por ser considerada uma doença que tem cura e cuja quimioterapia não teria um retorno econômico atrativo.

A comunidade científica pode contribuir com a busca de novos alvos e fármacos que sejam mais eficazes, seletivos e menos tóxicos, mesmo diante da impossibilidade de cultivo e inoculação do bacilo de Hansen.

\section{Referências Bibliográficas}

${ }^{1}$ Pandya, S. S. Hist. Cienc. Saúde - Manguinhos 2003, 10 (Sup. 1), 161. [CrossRef]

${ }^{2}$ Araújo, M. G. Rev. Soc. Bras. Med. Trop. 2003, 36, 373. [CrossRef]

${ }^{3}$ Sítio da Organização Mundial de Saúde. Disponível em:

<http://www.who.int/neglected diseases/diseases/e n/>. Acesso em: 10 outubro 2011.

${ }^{4}$ Sítio da Organização Mundial de Saúde. Disponível em:

$<$ http://www.who.int/gho/neglected diseases/lepros y/en/index.html> Acesso em: 10 outubro 2011. 
${ }^{5}$ Sítio da Organização Mundial de Saúde. Weekly epidemiological Record. Disponível em: <http://www.who.int/wer/2010/wer8535.pdf>. Acesso em: 10 outubro 2011.

${ }^{6}$ Sítio Portal da Saúde. Disponível em: $<$ http://portalsaude.saude.gov.br/portalsaude/noticia 44085/162/novos-casos-de-hanseniase-caem-15-emum-ano.html >. Acesso em 24 maio 2012.

${ }^{7}$ Macieira, S. Aspectos Microbiológicos do Mycobalerium leprae, Em Noções de Hansenologia. Opromolla, D. V. A., Centro de Estudos Dr. Reynaldo Quagliato, São Paulo, Bauru, 2000. [Link] [Link]

${ }^{8}$ Manual de Leprologia, Ministério da Saúde, Serviço Nacional de Lepra, Rio de Janeiro, Brasil, 1960. [Link]

${ }^{9}$ Eidt, L. M. Saúde e Sociedade 2004, 13, 76. [CrossRef]

${ }^{10}$ Plano Nacional de Eliminação da Hanseníase em nível municipal 2006-2010. Ministério da Saúde. Brasil, 2006. Disponível em: $<$ http://portal.saude.gov.br/portal/arquivos/pdf/hans eniase plano.pdf>. Acesso em: 20 outubro 2011.

${ }^{11}$ Souza, C. S. Simpósio: Hanseníase, Medicina, Ribeirão Preto, 1997, 30, 325. [Link]

12 Deps, P. D. Hansen Int., 2001, 26, 31. [Link]

${ }^{13}$ Beiguelman, B. Ciênc. Saúde Coletiva 2002, 7, 117. [CrossRef]

${ }^{14}$ Opromolla, D. V. A.; Ura, S. Atlas de Hanseníase, Instituto Lauro de Souza Lima, Bauru - SP, 2002. [Link]

${ }^{15}$ Ura S. Hansen Int. 2007, 32, 67. [Link]

${ }^{16}$ Goulart, I. M. B.; Arbex, G. L.; Carneiro, M. H.; Rodrigues, M. S.; Gadia, R. Rev. Soc. Bras. Med. Trop. 2002, 35, 453. [CrossRef] [PubMed]

${ }^{17}$ Kromann, N. P.; Wilhielmsen, R.; Stahl, D. Arch Dermatol. 1982, 118, 531. [Link]

${ }^{18}$ Opromolla, D. V. A. Contribuição ao Estudo da Terapêutica da Lepra. (Hanseníase) Bauru, SP, 1972. [Link]

${ }^{19}$ Ura, S. Dissertação de Mestrado, Universidade Estadual Paulista, Brasil, 2007. [Link]

${ }^{20}$ Hastings, R. C.; Franzblau, S. G. Ann. Rev. Pharmacol. Toxicol. 1988, 28, 231. [CrossRef] [PubMed]

${ }^{21}$ Legendre, D. P.; Muzny, C. A.; Swiatlo, E. Pharmacotherapy 2012, 32, 27. [CrossRef] [PubMed]

22 Arbiser, J. L.; Moschella, S. L. J. Am. Acad. Dermatol. 1995, 32, 241. [CrossRef] [PubMed]
${ }^{23}$ Chemoterapy of Leprosy. WHO Series Genova. 1994. [Link]

24 OMS. 768, 1988. Disponível em: $<$ http://whqlibdoc.who.int/trs/WHO TRS 768 spa.pd f>. Acesso: 22 novembro de 2011.

${ }^{25}$ Opromolla, D. V. A. Simpósio: Hanseníase, Capítulo IV, Medicina, Ribeirão Preto, 1997, 30, 345. [Link]

${ }^{26}$ Penna, G. O.; Martelli, C. M. T.; Stefani, M. M. A.; Macedo, V. O.; Maroja, M. F.; Chaul, A. An. Bras. Dermatol. 2005, 80, 511. [CrossRef]

${ }^{27}$ Brito, E. O. X.; Queen, S. M. F.; Pires, C. A. A.; Daxbacher, E. L. R. Hansen. Int. 2010, 35, 53. [Link]

${ }^{28}$ Matsuoka, M. Jpn. J. Infect. Dis. 2010, 63, 1. [Link]

${ }^{29}$ Pettit, J. H. S.; Rees, R. J. W. Lancet 1964, 2, 673. [CrossRef] [PubMed]

${ }^{30}$ Jacobson, R. R.; Hastings, R. C. Lancet 1976, 2, 1304. [CrossRef] [PubMed]

${ }^{31}$ Maeda, S.; Matsuoka, M.; Nakata, N.; Kai, M.; Maeda, Y.; Hashimoto, K.; Kimura, H.; Kobayashi, K.; Kashiwabara, Y. Antimicrob. Agents Chemother. 2001, 45, 3635. [CrossRef] [PubMed]

${ }^{32}$ Diório, S. M., Manini, M. I. P., Trino, L. M.; Sartori, B. G. C., Opromolla, D. V. A. Hansen Int. 2005, 30, 15. [Link]

${ }^{33}$ Sítio WHO recommended MDT regimens. Disponível em: $<$ http://www.who.int/lep/mdt/regimens/en/index.ht $\underline{\mathrm{ml}}$ >. Acesso: 22 novembro 2011.

${ }^{34}$ Guia para o Controle da hanseníase. Ministério da Saúde. Brasil, 2002. Disponível em: $<$ http://bvsms.saude.gov.br/bvs/publicacoes/guia de hanseniase.pdf> Acesso em: 20 outubro 2011.

${ }^{35}$ Visschedijk, J.; Broek, J.; Eggens, H.; Lever, P.; Beers, S.; Klatser, P. Trop. Med. Int. Health 2000, 5, 388. [CrossRef] [PubMed]

${ }^{36}$ Diniz, L. M.; Catabriga, M. D. S.; Filho, J. B. S. Rev. Soc. Bras. Med. Trop. 2010, 43, 695. [CrossRef] [PubMed]

${ }^{37} \mathrm{Ji}$, B.; Perani, E. G.; Petinom, C.; Grosset, J. H. Antimicrob. Agents Chemother. 1996, 40, 393. [PubMed] [Link]

38 Ji, B.; Perani, E. G.; Grosset, J. H. Int. J. Lepr. Other Mycobact. Dis. 1992, 60, 556. [PubMed]

${ }^{39}$ Dhople, A. M. Int. J. Antimicrob. Agents 1999, 12, 319. [CrossRef] [PubMed]

${ }^{40}$ Dhople, A. M. Int. J. Antimicrob. Agents 2002, 19, 


\section{1. [CrossRef] [PubMed]}

${ }^{41}$ Hajime, S.; Haruaki, T.; Katsumasa, S.; Satoshi, D. Int. J. Lepr. Other Mycobact. Dis. 1994, 62, 43. [PubMed]

42 Haruaki, T.; Hajime, S. Int. J. Lepr. Other Mycobact. Dis. 1993, 61, 255. [PubMed]

43 Shanmugam, A.; Anbazhagan, V.; Natarajan, J. Med. Chem. Res. 2012, No Prelo. [CrossRef]

${ }^{44}$ Agnew, C. R. J.; Warrilow, A. G. S.; Burton, N. M.; Lamb, D. C.; Kelly, S. L.; Brady, R. L. Antimicrob. Agents Chemother. 2012, 56, 391. [CrossRef] [PubMed]

${ }^{45}$ Gelber, R; Andries, K.; Paredes, R. M. D. Andaya, C. E. S.; Burgos, Antimicrob. Agents Chemother. 2009, 53, 3989. [CrossRef] [PubMed]

${ }^{46}$ Andries, K.; Verhasselt, P.; Guillemont, J.; Gohlmann, H. W. H.; Neefs, J.-M.; Winkler, H.; Gestel, J.; Timmerman, P.; Zhu, M.; Lee, E.; Williams, P.;
Chaffoy, D.; Huitric, E.; Hoffner, S.; Cambau, E.; Truffot-Pernot, C.; Lounis, N.; Jarlier, V. Science 2005, 307, 223. [CrossRef] [PubMed]

47 Urlyapova, N. G.; Yushchenko, A. A.; Daudova, A. D.; Makarov, V. A. Bull. Exp. Biol. Med. 2007, 143, 356. [CrossRef] [PubMed]

48 Makarov, V.; Riabova, O. B.; Yuschenko, A.; Urlyapova, N.; Daudova, A.; Zipfel, P. F.; Mollmann, U. J. Antimicrob. Chemother. 2006, 57, 1134. [CrossRef] [PubMed]

${ }^{49}$ Barbosa-Filho, J. M.; Júnior, F. A. N.; Tomaz, A. C. A.; Athayde-Filho, P. F.; Silva, M. S.; Cunha, E. V. L.; Souza, M. F. V.; Batista, L. M.; Diniz, M. F. F. M. Rev. Bras. Farmacogn. 2007, 17, 141. [CrossRef]

50 Martelli, C. M. T.; Stefani, M. M. A.; Penna, G. O.; Andrade, A. L. S. S. Rev. Bras. Epidemiol. 2002, 5, 273. [CrossRef] 